\title{
Defect Analysis and Process Parameter Optimisation in Sand Casting
}

\author{
Kumar Manoj, S. S. Banwait
}

\begin{abstract}
M/s. Boparai Metals, a small scale industry situated in Industrial Area, Mohali, Punjab is manufacturing and supplying automotive and non automotive component to tractor companies in Punjab and aiming to provide the best solutions. The company is facing the problem of castings defects i.e. porosity, hot spot and shrinkage in cooler plate during the Sand Casting process. In this work, the study of existing process was done to find the root cause of the problem. Three dimensional gating system of cooler cover plate were modified by using UG$N \mathrm{X}$ software. The models were imported using ADSTEFAN software for simulation of SAND-CASTING process. Based on the specification of cooler cover plate material, cast iron moulds in the green sands and input process parameters; design calculation of casting model was undertaken. Three case studies i.e. analysis based on the solidification method, were carried out for defect analysis of casting component and simulation study was done for process parameter optimization using ADSTEFAN software. It was observed that molten metal enters at critical location of cover plate causing turbulence in metal flow and solidification was not getting achieved in the directional way, thereby resulting in shrinkage defect. The shrinkage defect was removed by providing risers at proper location.
\end{abstract}

Keywords: Sand Casting, Simulation, Shrinkage Defect, ADSTEFAN software

\section{INTRODUCTION}

Casting is more than 5000 years old process. It is mentioned in several Sanskrit works like Shilpashastra, Stahapatyaveda, Atharvaved etc. Vishwakarma and Maya are chief engineers of gods and demons respectively. Equipments used in casting are mentioned the Rigveda. Equipments include name Cupula (Dhamatri), Crucible (Gaharama Aranmaya), Blower (Bhastri) etc. Idols used in worship, were made from casting. To achive perfection strict rules were led down in terms of Mudra (stance), Talmaya Proportion), etc. Factors influencing mechanics of sand casting: The major factors which influences the mechanics of casting are: heating and pouring of metal (pouring temperature, pouring rate, turbulence), fluidity and its rate, solidification and cooling, Shrinkage, pouring time, pattern / mould design, casting attributes properties, air pressure and metal filling rate. To obtain a sound casting it is necessary to control adequately the various factors affecting the casting process,

Revised Manuscript Received on August 15, 2020.

* Correspondence Author

Kumar Manoj*, Lecturer, Department of Science and Technology, Govt. Polytechnic Adityapur, Jharkhand, India. Email:kmanojmech@gmail.com

Prof. (Dr.) S S Banwait, Dean, Research \& Development and Professor, Department of Mechanical Engineering, National Institute of Technical Teachers Training and Research, Chandigarh, India.

(C) The Authors. Published by Blue Eyes Intelligence Engineering and Sciences Publication (BEIESP). This is an open access article under the CC BY-NC-ND license (http://creativecommons.org/licenses/by-nc-nd/4.0/) like casting and pattern design, moulding procedure, melting and pouring of molten metal. Design considerations include promoting directional solidification when designing the mould (i.e. riser should be properly dimensioned and located), avoiding hot spots and ensuring easy pattern withdrawal.

\section{LITERATURE REVIEW}

Many different strategies have been adopted by earlier researchers to tackle such issue of defects in different types of casting materials and how they have been reduced. Some of them have used simulation softwares and have tried to optimise the process parameters for minimising the defects. Shubham Sanjay Sorate, et al.[5] focused the study on route cause analysis of blow holes and shrinkage cavities defect which causes heavy rejection in casting. A defect in casting deteriorates casting surface quality and mechanical properties. For casting with thicker section, finding the hot spot is very important. Optimizing of gating system was done by using simulation software with proper location of feed aids like Riser, vent holes, chills etc. Brijendera Prajapati, et al.[6] have studied shrinkage defect in Hand Wheel casting. Defects were eliminated by using casting simulation software ADSTEFAN. Design processes was carried out on a trial and error basis. Shrinkage porosity analysis was done by introducing new Gating Design followed by several iterations including runner length change and riser introduction. Results indicated shrinkage porosity reduction and yield improvement. Khan, M.A.A. \& Sheikh, A.K.,[7] has compared eight different casting simulation software. Their key conclusion include: (i) casting simulation software simulates most of the casting processes but reliability of results depends on how accurately the simulation is set up by defining material properties, meshing, boundary conditions etc. (ii) Most of the software is based on FDM, FEM, FVM solution. FEM improves simulation time by $10 \%$ because it needs less number of cells to define casting geometry as compared to FDM and FVM. (iii) Strength of the software is its predictive power regarding defects. Vipul M Vasava, and Prof D. R. Joshi[8] has identified the porosity formation in steel casting, besides hotspot, blowholes using computer simulation. Simulation of gating system, riser design, location is used appropriately for reducing porosity formation in casting component. Hodbe G.A., et al.[9] has studied the casting process in contact wheel casting to improve design and manufacture of a defect free part. The critical step in casting process is solidification of molten metal in mould cavity. Defects like volumetric shrinkage, porosity, blowhole occurs during this and affects the quality. Defects are seen when part is completely manufactured and testing is done. In traditional casting redesigning of feeder, gating system etc is done and casting is repeated.

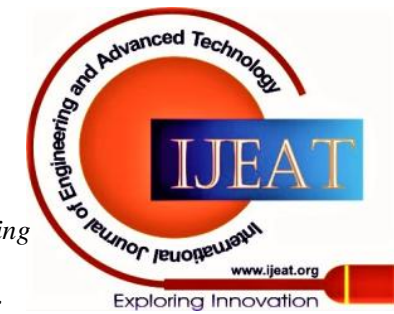


It affects the rate of production directly. Smart methoding and advance simulation casting software AutoCast used to address these problems.

Snehal Sunthakar, et al.[10] has investigated that the yield of gating system of casting is increased by increasing the number of cavities. But by increasing the number of cavities, it is seen that the number of defects also increase. Advantage of casting is it can manufacture large number of parts in less time. Limitation of casting process is that defects in casting are not seen while producing it. Defects are seen after parts are removed from mould so it is necessary to analyse the gating system. Analysis of gating system will help identify and remove the defects, reducing loss of money, time and material. ADSTEFAN software was used for analyzing the gating system. Mrs Desai P.P, et al.[11] have described the use of casting simulation for yield improvement and reducing shop-floor trial. Casting simulation simulates the casting process and gives virtual casting process for molten metal flowing and solidifying in the cavity. It also predicts internal defects location like blowholes, shrinkage porosity. Modified gating system is used to obtain sound casting. Energy and resources required are saved by improving yield.

\section{METHODOLOGY}

The component drawing received from the company was studied further for evolving the mould design and optimization of processes parameters.

Design Calculation for Casting Model The design calculation for casting model i.e. pouring capacity of a ladle, bunch weight calculation, gating design, overflow design and venting were given by the company are as follows.

Data of Component(Cooler Plate) : Mass of the Component $=3.529 \mathrm{~kg}$, Number of components in a bunch $=6$, Overflows and Runners mass $=5.78 \mathrm{~kg}$, Total mass $(\mathrm{m})$ $=3.529$ X $6+5.78=26.9 \mathrm{~kg}$, Density of metal, $(\mathrm{d})=7.2$ $\mathrm{gm} / \mathrm{cm}^{3}$, Volume of the component $\left(V_{t}\right)=\mathrm{m} / \mathrm{d}=3736 \mathrm{~cm}^{3}$, Minimum wall thickness of the component $=6 \mathrm{~mm}$, Flow rate $=1.8 \mathrm{~kg} / \mathrm{sec}$., Filling time: $15 \mathrm{sec}$. According to the flow rate and casting weigh, the filling time is taken as 15 sec.

Ingate Calculation: Casting thickness (front of gate): 50.4 $\mathrm{mm}$, Gating ratio: 3:1:2 mm, Ingate thickness: $5.5 \mathrm{~mm}$, Runner thickness: $26 \mathrm{~mm}$,

Pouring Temperature : $1340^{\circ} \mathrm{C}$ to $1380^{\circ} \mathrm{C}$, Venting Design: as per the experience, depending upon the antigravity

flow.

Simulation of sand-casting process parameters using ADSTEFAN software : For simulation of sand-casting process parameters, three case studies were considered and simulated using ADSTEFAN software. The description of case studies as well as software are given.

Case Studies for Analysis : The case studies for simulation of sand-casting parameters are as follows: CASE I : Analysis based on metal flow and solidification: Analyzing the defects like blow holes, pin holes, shrinkage etc, CASE II : Analysis based on gating design changes, CASE III: Analysis based on addition of the casting attributes like riser, sleeves, etc.

All the three case study analysis comprises the following steps for simulation : (i) Flow simulation of temperature : Flow simulation of temperature shows filling \% and flow time with respect to temperature, (ii) Flow simulation of pressure: This simulation shows the pressure (atm) in the cavity, (iii) Flow simulation of Velocity: This simulation shows the velocity value in the cavity, (iv) Vorticity of metal in the cavity: The simulation shows the vorticity (turbulence) generated in the cavity at the time of metal fillings, (v) Hotspot in casting: The simulation shows the hotspot in the casting due to rapid drop in temperature at the time of filling, (vi) Solidification simulation: This simulation finds shrinkage location in the cavity. ADSTEFAN software was used for simulating these parameters and selection of their levels with simulation experiments. In order to perform the mould filling with solidification simulation of automotive part, the commercial ADSTEFAN software was used. This software solves simultaneously three-dimensional transient fluid flow and solidification problems with free surface. Different stages in simulation used were i) Data gathering ii) Method design iii) Simulation iv) Optimization v) Project closure vi) Discussions.

\section{RESULTS AND DISCUSSION}

The following process parameters were used in order to mould the casting.

Gating ratio: The gating was designed by M/s. Boparai Metals by consulting the specialist. The location of runner riser and gating system was designed on the basis of their experience in defining the location. They referred to the location of the thick masses in casting in order to define the position of the riser.

Pouring temperature : As the SG iron starts melting above $1145^{\circ} \mathrm{C}$, the tapping temperature of the molten metal in the furnace was noted as 1410 to $1420^{\circ} \mathrm{C}$. The liquid metal was transported from the furnace to the moulding area. Some temperature drop in the metal was noticed. The transportation mode is manual through small ladle. A temperature drop of 40 to $50^{\circ} \mathrm{C}$ was observed at the time of metal transportation. So, the pouring temperature was noted as $1340^{\circ} \mathrm{C}$.

Cavity filling time : Based on the flow rate of the ladle and the experience of $\mathrm{M} / \mathrm{s}$. Boparai Metals, the casting filling time was taken as 15 sec.

Design calculations: Figure 1 shows design of the casting model. The drawing was given by $\mathrm{M} / \mathrm{s}$. Boparai Metals, which was done with the help of NX-UG software.

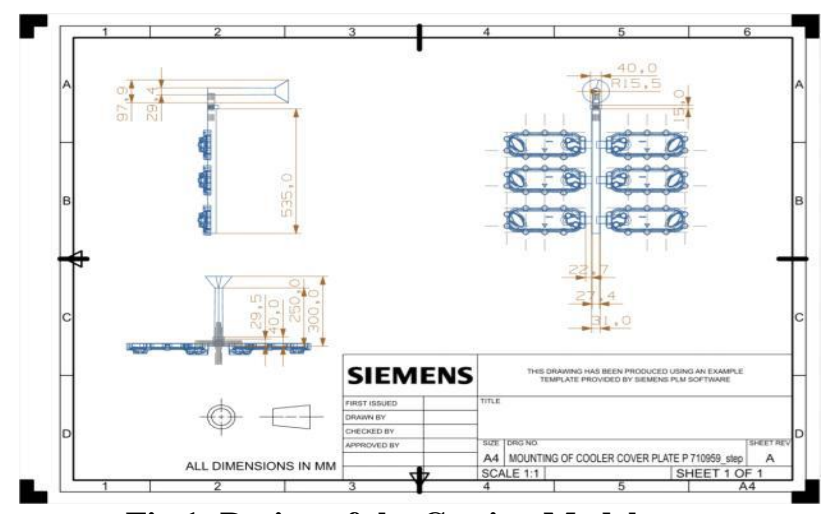

Fig 1: Design of the Casting Model

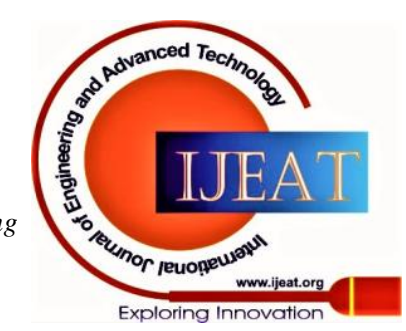


SIMULATION STUDY : With the help of ADSTEFAN casting simulation software various results related to metal filling and solidification were obtained. ADSTEFAN predicts more than 25 results related to the metal flow and more than 19 results related the solidification. Some of the outputs of the ADSTEFAN are as follows.

Metal temperature : With the calculated ratio and the designed gating it was found that there is a temperature drop of the metal at the time of metal filling as the pouring temperature was $1380{ }^{\circ} \mathrm{C}$ and according to the material properties, the liquidus temperature of the material was $1050^{\circ} \mathrm{C}$ and solidus temperature of the casting was $1045^{\circ} \mathrm{C}$, having the difference of 5 degree in getting metal solidified. Below image in Fig. 2 shows the temperature drop of metal just after filling.

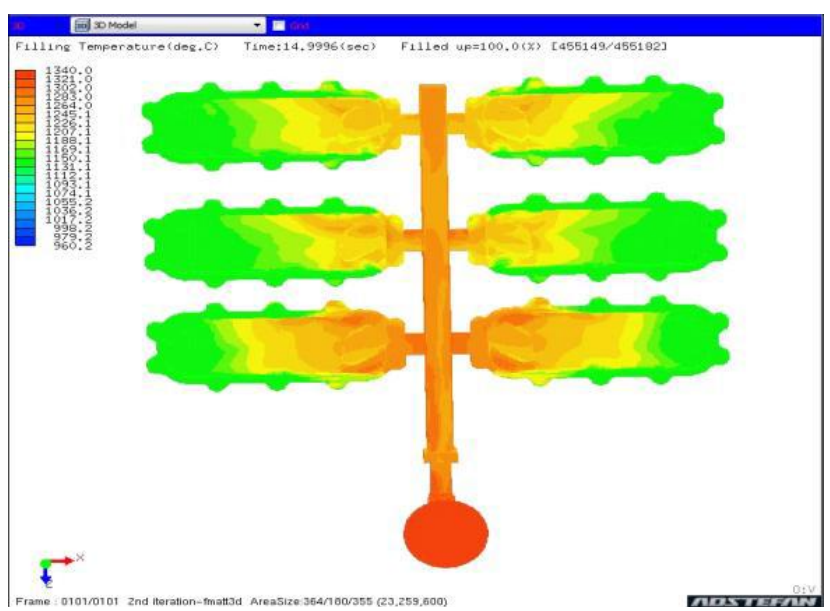

Fig 2: Temperature distribution in casting

Metal pressure : As per the observation of the metal flow, it was seen that the metal pressure was increasing at the time of metal filling but once the cavity was filled, the pressure distribution was uniform all over the casting. The pressure value inside the cavity was found equal to the atmospheric pressure as shown in blue colour. It means the casting will come sound as per the pressure distribution.

Filling velocity : The maximum velocity was found at the gate area only. As per the metal flow, it was a uniform velocity. The uniform value of velocity was seen less than $30 \mathrm{~cm} / \mathrm{s}$ that means the metal movement is slow which doesn't lead to slag entrapment or sand erosion.

Vorticity (Turbulence) in Molten Metal : The maximum turbulence means maximum chances of getting casting defect like pinholes, air entrapment and slag etc in the casting. As the casting gating is uniform so no major issue has arisen in the casting. Turbulence plays a very vital role in getting a sound casting. It is not easy to flow the molten metal without turbulence. So the best practice of the gating is not to make the flow turbulent. It should be smooth. In order to achieve a smooth flow, the gating are designed with less curves and edges by providing chamfer and edge blend in the pattern and same in the sand mould.

Solid fraction - hotspot : As per the software prediction hotspot defect was not found as the filling happened smoothly, based on temperature drop only, cold short was seen in the casting. In Figure 3 shows the hotspot in the casting, where no area is seen in red colour. If any predicted area is having red colour that can be judged as the hotspot.

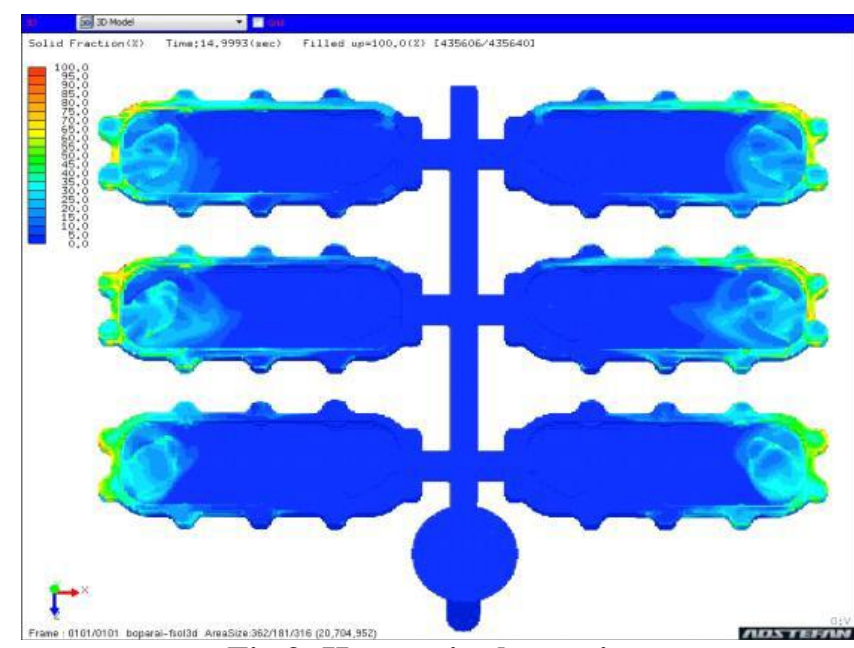

Fig 3: Hotspot in the casting

Solidification of Casting: Figure 4 is predicting the solidification of the molten metal on the basis of critical value of solidification. Fs $=0$ means when the metal is in liquid phase; in the phase 2 ADSTEFAN predicts the when the metal is changing the state from liquid to semi solid, in phase 3 ADSTEFAN predicts the solidification when the state of metal is changing from semi solid to solid phase and the final stage is $\mathrm{Fs}=1$ that means metals is completely solidified.

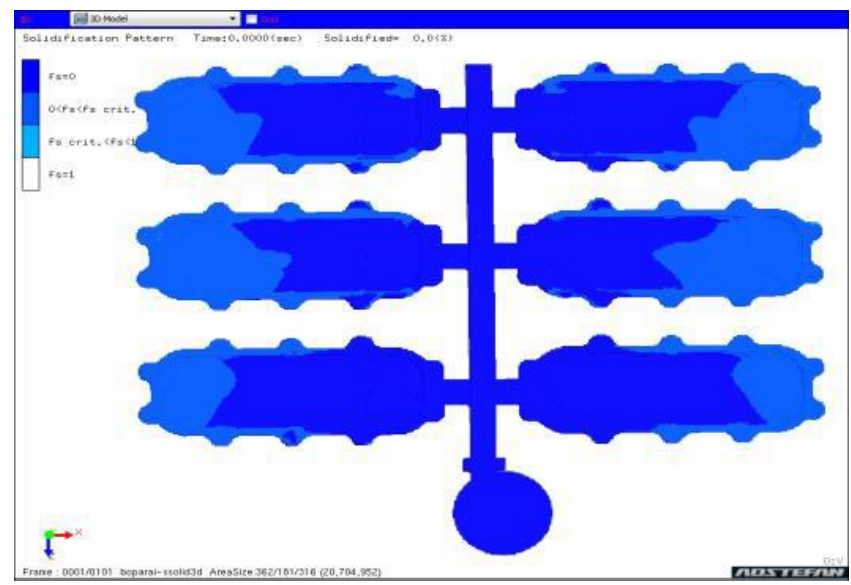

Fig 4: Solidification of casting

Shrinkage : Whenever there is un-directional solidification, it leads to the shrinkage in the casting, ADSTEFAN predicts the shrinkage based on the filled ratio. The observation for the getting shrinkage is when the metal is solidified it forms the cavity empty space in the casting which means the meshes made by the software will become empty and doing the scaling the software will highlight the area where there are empty meshes that will predict the shrinkage. Scaling is done based on following level of measure:, Scaling between 1 to 10 : level 4 of shrinkage, Scaling between 11 to 40 : level 3 of shrinkage, Scaling between 41 to 75 : level 2 of shrinkage, Scaling between 76 to 98 : level 1 of shrinkage, which is scaled from 1 to 98, knowing all the level of shrinkage and red colour predicting the high level of shrinkage and blue colour predicting the low level of shrinkage. ADSTEFAN predicts the volume of shrinkage depending upon the FDM technology of the software and mesh calculation.

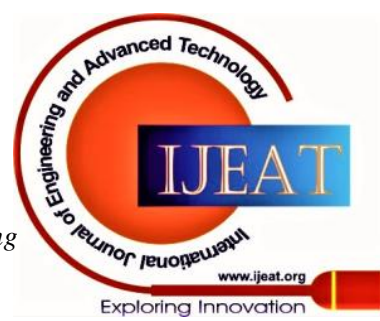


Figure 5 gives the clear prediction/values about the volume of the shrinkage. The observations for the results reading are: (i) 66, 0.527992, (i) : Serial Number, 66 : number of meshes associated in the shrinkage, 0.527990 : Volume of shrinkage in $\mathrm{cm}^{3}$,

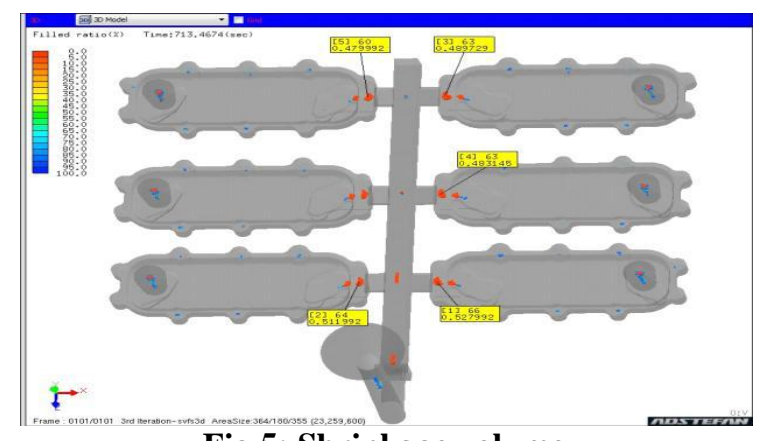

Fig 5: Shrinkage volume

It is found from the solidification pattern that the metal is getting last solidified inside the casting which is leading to the shrinkage in the casting. Two major defects (i) cold shut and (ii) shrinkage was observed. Corrective action was required (with help from casting experts) to remove the cold shut. The gating ratio was changed because increase in the gate area will lead to high metal flow. It will also affect the filling of the metal.

\section{OBSERVATIONS FROM SIMULATION STUDY}

The results were observed keeping cold shut and shrinkage of the casting in focus. ADSTEFAN software predicts the cold shut and degree of soundness of casting. Following observations were considered, w.r.t. other output of the software.

Metal temperature: In comparison with the last gating system, modification was done and positive results were found. The minimum temperature of the casting was more than the solidus temperature of the casting that is $1045^{\circ} \mathrm{C}$. According to the software prediction, the lowest temperature of the casting is $1160^{\circ} \mathrm{C}$ which is much more than the solidus temperature. This give clear indication that the changes made in the gating system helps in getting the casting with high temperature and cold shut free.

Turbulence : In comparison with the value of last turbulence, it was found that with changes in the gating system of the casting, the maximum value of the turbulence of the casting has been decreased. The older maximum value was $494.9 \mathrm{rad} / \mathrm{sec}$ and new value of turbulence obtained was $227.4 \mathrm{rad} / \mathrm{sec}$. This happened due to the change in the cross-sectional value which helped the metal to flow more smoothly. As observed in the figure 6, this was also a good sign of gating improvement.

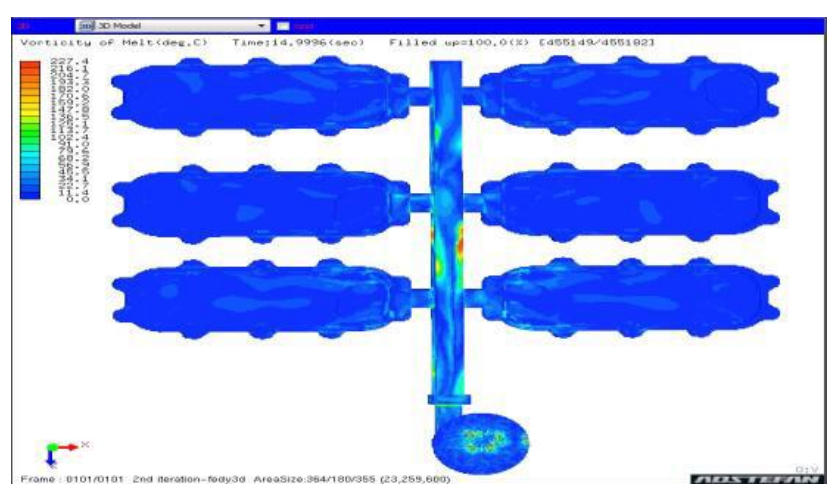

Fig 6 Turbulence of Metal
Shrinkage in Casting : Keeping the same scale, it was found that increasing the cross-section of the gating and runner, resulted in the reduced shrinkage which earlier was observed in front of the ingate. This was achieved due to the directional solidification in the casting. For sound casting, gating should be designed in such a way that casting should solidify first then gating and then runner or riser. According to the directional solidification achieved at the gate, it was made shrinkage free but having a heavy section at the opposite of casting directional solidification were not fully achieved and it leads to the shrinkage defect in casting. The area opposite to the ingate to the casting has transformed to the liquid phase form. ADSTEFAN is predicting the few blue coloured areas that means this area is yet to solidify and rest of the area has been solidified. In order to get the sound casting the whole casting should get directionally solidified. But sometime the geometry of the casting is typical that leads to the un-directional solidification and results in the shrinkage defect.

Riser at the Shrinkage Area : Riser is added at the shrinkage area, for removing the defect. The riser calculation was done with the ratio of $1: 3$, that means the section thickness at the riser area should be 3 times to the casting thickness

Temperature Distribution : Figure 7 is predicting the temperature distribution which clearly point to (i) Pressure distribution was same. (ii) Turbulence was controlled. (iii) No cold shut was found. Solidification was checked and found that after adding the riser to the casting, directional solidification was achieved in the casting. It was due to the proper location of riser.

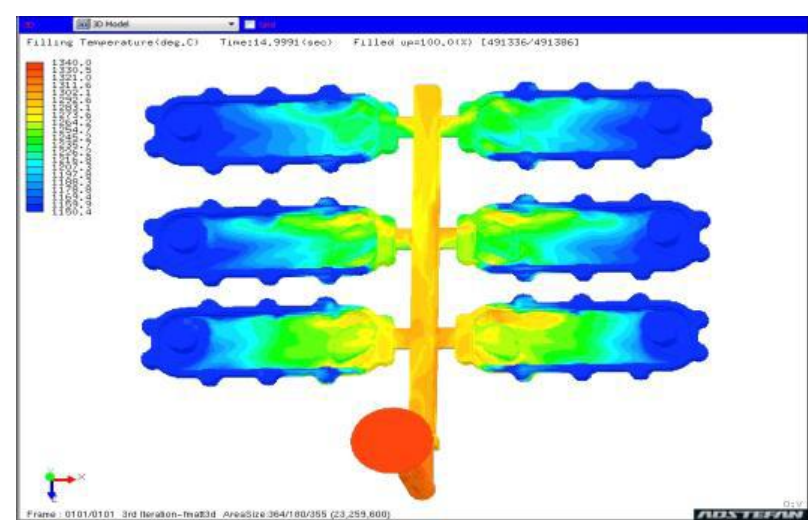

Fig 7 Temperature distribution

Solidification of Casting : With the effect of the riser feeding to the casting, the shrinkage was shifted from casting to the riser and sound casting was obtained. Additional riser helped in getting the sound casting, at the time of metal solidification, riser supplied the extra metal to compensate the shrinkage in the casting. There was difference in the solidification pattern observation of casting with and without riser. Figure 8 depicts the solidification pattern in the casting. The metal fed by the riser to the casting and results in achieving the sound and specifically shrinkage free casting particularly at the required area.

Published By:

Blue Eyes Intelligence Engineering and Sciences Publication 


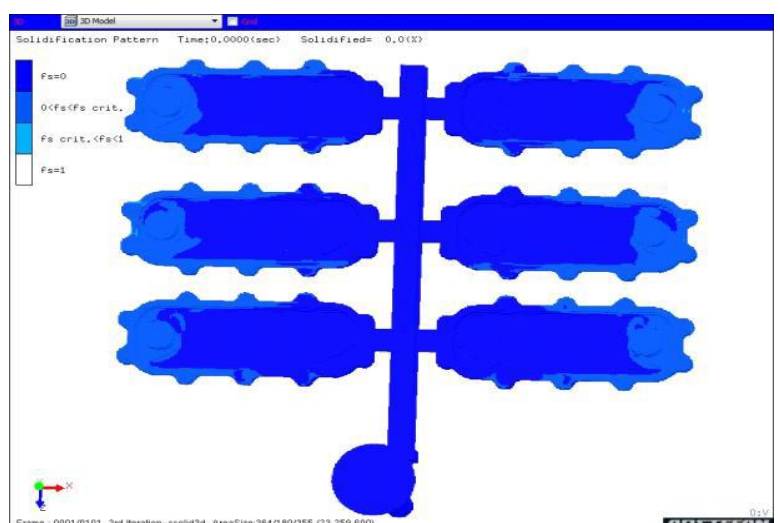

Fig 8 Solidification pattern after metal filling

The ADSTEFAN software is clearly predicting that the riser is yet to get solidify whereas the casting is solidified. This is helping in achieving the directional solidification and hence it can be seen that no shrinkage is coming in the casting. With reference to adding riser to the casting, it has been found that the shrinkage is shifted from casting to the riser. Figure 9 shows the shrinkage found in the riser which was earlier seen in the casting, this is due to the directional solidification.

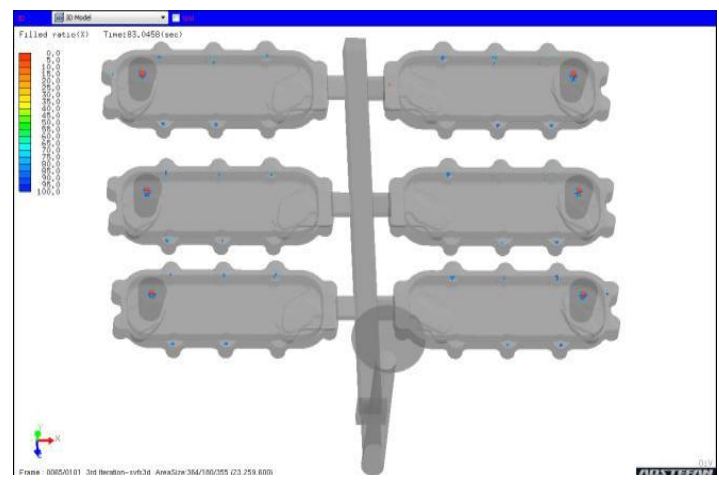

Fig 9 Shrinkage in the casting

It can be seen that red colour is found in riser only, which shows that shrinkage is removed from the casting and shifted to riser. After cutting the riser from casting there will be no defect in the casting, so, defect free casting was achieved.

Limitations of the present work : Lower Dimensional Accuracy: This process in general provides less dimensional accuracy than other casting processes commonly used. Pattern Maintenance : Pattern can be bulky requiring storage management. Surface Finish: Sand castings are normally have rough surface finish as compared to other casting processes. Unavoidable Defects: Due to metallurgical variation in process and quality shrinkage, pouring metal defects are unavoidable. Post Processing: For tighter tolerance, secondary machining operations are required frequently.

Future scope of work : With the help of ADSTEFAN software, the best gating system suitable for making sound casting can be made and results can be verified with/without the shop floor trial casting. Present work is open for further modification and improvement. Following scope of work may be considered. Improving the efficiency of the furnace, by adding economical pollution control devices. Better disposal of foundry waste and different gating and feeder design.

\section{CONCLUSION}

It can be concluded that, with change in Gating ratio from 3:1:2 to $3: 1.5: 3$ and proper location of riser, directional solidification was achieved in the casting. Shrinkage in the casting was shifted to the riser. Riser supplied the required volume of metal for reducing the shrinkage in casting and defect free casting was obtained.

\section{REFERENCES}

1. B. Ravi, "Metal casting computer aided design and analysis", ISBN978-81-2726-9, sixth printing Sep. 2011, PP 4-7.

2. S.Kalpakjian, S.R. Schmid, "MANUFACTURING PROCESS FOR ENGINEERING MATERIALS", 5th edition PEARSON. Publisher: Dorling Kindersley (India) Pvt Ltd. Copyright (C) 2009. ISBN- 97881-317-0566-7

3. AFS Birmingham, "TIMELINE OF CASTING TECHNOLOGY," PP. 1-5. (Www.afsbirmingham.com) 4. P. N. Rao Manufacturing Technology: Foundry Forming and Welding, 4e, Vol. 1. Publisher: McGraw Hill Education (India) Private Limited. Fourth reprint 2014 ISBN- 13:978-1-25-906257-5

4. Shubham Sanjay Sorate, Priya Umesh Kanase, Professor Bhusan Shankar Kamble, professor Mohan Shadashiv Sawant, "Effective use of Casting Simulation for Improving Bearing Housing Casting Yield" 2017 IJSRSET, Vol. 3, issue 2, 2395-1990, PP 16-26.

5. Brijendera Prajapati, Hari Dhakal, Mukesh Regmi,"Defect analysis of hand wheel casting using computer aided casting simulation technique" IJMET vol.7, issue 5 Sep-Oct 2016, PP 46-56

6. Khan, M.A.A. \& Sheikh, A.K., " A Comparative Study of Simulation Software for Modelling Metal casting Processes," https://doi.org/10.2507/IJSIMM17(2)402, ISSN 1726-4529, Int j simul model 17 (2018) 2, PP 197-209.

7. Vipul M Vasava, Prof D. R. Joshi, "Identification of Casting Defects by Computer Simulation-A Review," IJERT, ISSN: 2278-0181,Vol. 2, Issue 8, August-2013, PP 2550-2555.

8. Hodbe G.A., Shinde B.R., "Design And Simulation Of LM 25 Sand Casting For Defect Minimization," Materials Today: Proceedings 5 (2018) 4489-4497, ICMPC 2017 www.materialstoday.com/proceedings

9. Snehal Sunthakar, Prajakta Patil, G. N. Maranholkar, "Analysis of Gating System of a Casting to Increase the Productivity and Yield," IJSR, ISSN (on line) 2319-7064, Vol. 6, Issue 6, June 2017, PP 394 398.

10. Mrs Desai P.P, Jadhav Sohan, Lohar Vishal, Kamble Rajat, Gowdhan Prasad, Katwal Amol, [7] "Use of Casting Simulation for Yield improvement", e-ISSN:2395-0056, P-ISSN: 2395-0072 International Research Journal of Engineering and Technology IRJET Volume:06 ISSUE:03 Mar 2019 PP 7704-7707

\section{AUTHORS PROFILE}

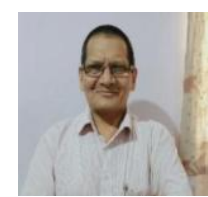

Kumar Manoj is a Lecturer in Mechanica Engineering at Govt. Polytechnic Adityapur, Jharkhand under Department of Science and Technology, Govt. of Jharkhand. He joined Govt. Polytechnic as a lecturer (Mech Engineering) through Jharkhand Public Service Commission in 2008. Qualifications He did matriculation with 78\% marks ( BSEB Patna). He did I. Sc from St. Xavier's College, Ranchi ( 1st div BSEB Patna). He completed BSc Engineering (Mech Engineering) from MIT Muzaffarpur, BIHAR UNIVERSITY ( 68\%).He is pursuing M.E. (Mech Engineering) under QIP (Poly) Scheme of AICTE at NITTTR Chandigarh for the Year 2017-18 with approval of Govt. of Jharkhand.Contact Detail: Govt. Polytechnic Adityapur, Industrial Area, $832109 \quad$ (Jamshedpur), Jharkhand, Ph: 06572383303 Email:kmanojmech@gmail.com, Mobile No. 7004581112

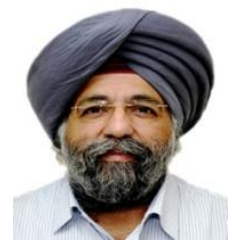

Prof. (Dr.) S S Banwait, Dean, Research \& Development and Professor of Mechanical Engineering at National Institute of Technical Teachers Training and Research, Chandigarh 160019 INDIA. 


\section{Defect Analysis and Process Parameter Optimisation in Sand Casting}

He obtained his BE (Mechanical Engineering from Rani Durgavati University, Jabalpur.) ,M.Tech (Mechanical Engineering from IIT Delhi) and $\mathrm{PhD}$ (Mech. Engg) from Thapar University, Patiala. He has over 34 Years of Industry, Teaching and Administrative Experience. He has guided more than 100 masters dissertation and 08 Ph.D. work, presently supervising 10 M.E. and 02 Ph.D. research scholars. He has over 100 Publication in International and National Journals and proceeding of International Conferences / Seminars to his credit. He has also authored 03 technical books. His areas of interest include CAD/CAM \& Robotics, Design for consumers, Computer Based Production Management and Triboloy. 